\title{
Electric Propulsion Naval Ships with Energy Storage Modules through AFE Converters
}

\author{
So-Yeon Kim*, Sehwa Choe*, Sanggi Ko*, Sungmin Kim*, and Seung-Ki Sul ${ }^{\dagger}$ \\ $\grave{\dagger}^{*}$ Department of Electrical and Computer Engineering, Seoul National University, Seoul, Korea
}

\begin{abstract}
This paper proposes a novel electric propulsion system for naval ships, which consists of Active Front End (AFE) converters directly connected to battery Energy Storage Modules (ESMs). Employing the proposed AFE converters with ESMs in the power systems of naval ships can enhance the reliability and quality of the electric power. Furthermore, the fuel-efficiency of the generator can be improved by a higher loading factor of the generator and its prime movers. The proposed AFE configuration does not require an additional dedicated DC/AC converter for the ESMs. Instead of that, the AFE converter itself can control the DC link voltage and the discharging and/or charging of the ESMs. A control scheme to achieve these control objectives is also presented in this paper. The overall power system, including the generators and electrical loads of a naval ship, is implemented by a small scaled Power Hardware-In-the-Loop (PHIL) simulator. Through this experimental setup, the proposed system configuration and the power control strategies are verified. It is shown that the fuel-efficiency and transient dynamics can be improved in the normal and contingency operation modes.
\end{abstract}

Key words: Active front end converter, Energy storage module, PHIL, Ship integrated power system

\section{INTRODUCTION}

In naval shipbuilding yards, there has been increasing interests for Integrated Power System (IPS) over conventional mechanical power system, which is shown in Fig. 1 [1], [2]. The benefits of IPS are condensed into a few factors as follows.

1) Fewer engines are installed resulting in greater fuel efficiency and reduced maintenance. (Increased fuel-saving)

2) It eliminates the long shaft which connects the engine and propeller, which is a weakness of navy ships in combat situations, and the electric distribution can be reconfigured rapidly by multiple redundant cables. (Higher reliability)

3) Ship propulsion control, such as maneuvering operation, is superior when compared to the mechanical control of geared propulsion systems because the propulsion motor is directly connected to the propeller. (Greater maneuverability)

Manuscript received Jun. 10, 2013; accepted Dec. 12, 2013

Recommended for publication by Associate Editor Rae-Young Kim.

${ }^{\dagger}$ Corresponding Author: sulsk@plaza.snu.ac.kr

Tel: +82-2-880-7243, Seoul Nat'l University

*Dept. of Electrical and Computer Eng., Seoul National University,

Korea

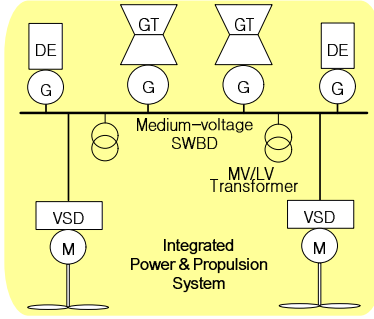

(a) Integrated power system.

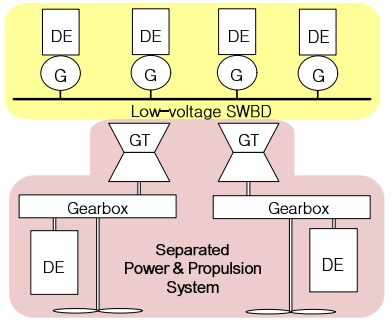

(b) Mechanical power system.
Fig. 1. Ship's electric power and propulsion power system. DE, Diesel-engine; GT, Gas-Turbine; SWBD, Switchboard; VSD, Variable Speed Drive; G, Generator; M, Motor

4) A large amount of the propulsion power can be utilized for ship service or mission loads such as high power radar, sonar, laser weapons, etc. (Increased power availability)

5) It improves the residential environment for the ship's crew by reducing mechanical noise and maintenance demands. (Improved residential environment)

Despite years of research on the IPS of naval ships, the technological development in propulsion motors and their power electronics drive systems are still challenging in terms of deciding the most appropriate IPS configuration. IPS should be designed to have an optimized configuration with reduced 


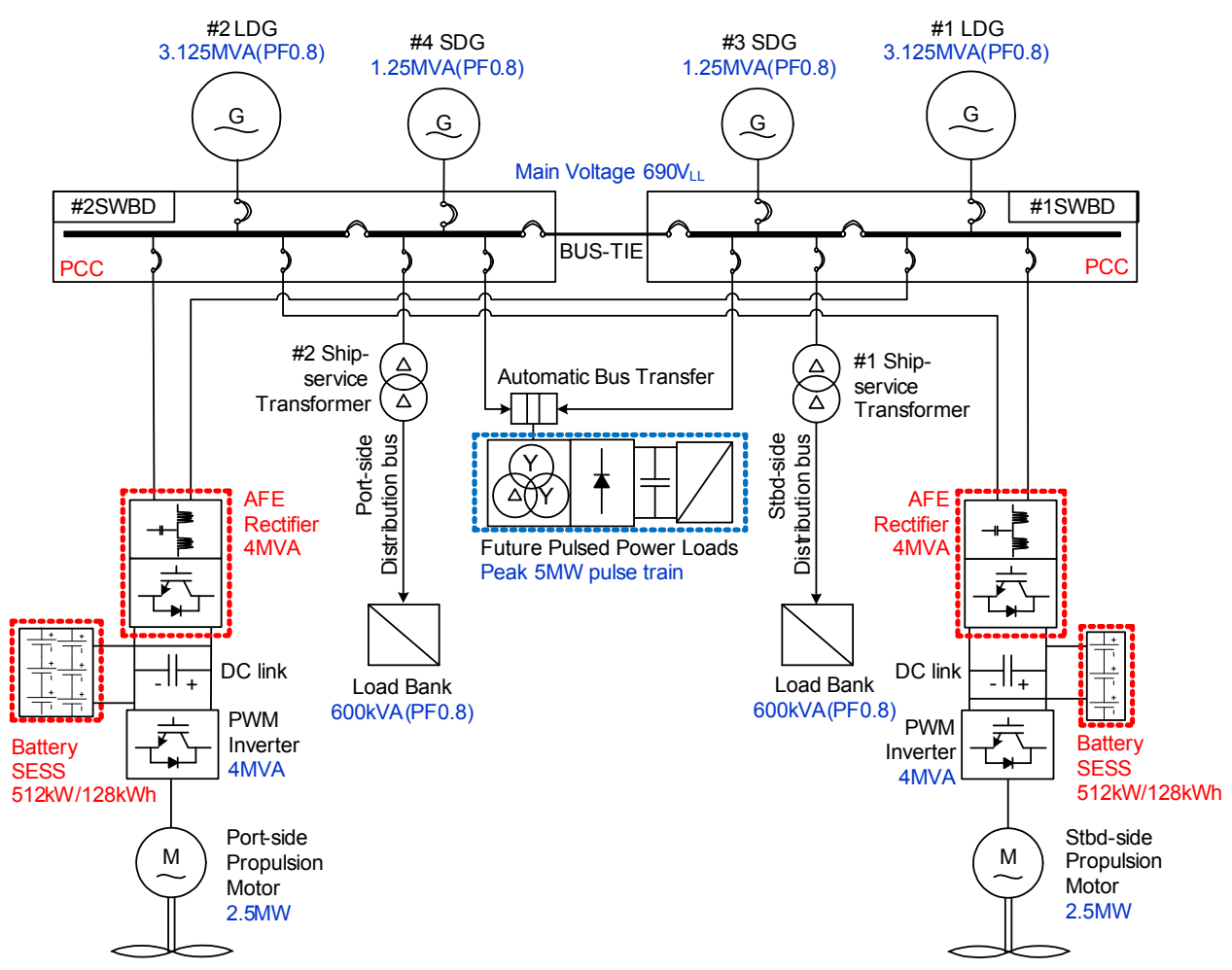

Fig. 2. Single line diagram of proposed IPS.

lifetime-fuel costs, increased power-reliability by ensuring a stable power grid, and reductions in system size and weight. Because a ship's machinery room is restricted when it comes to installing various capacity generators, a lot of research has been carried out on this issue. This research has include DC distribution and machine designs for high power density [3], [4]. In addition, Single Generator Operation (SGO) or a minimum number of generators is regarded as a practical solution in terms of a fuel-efficient operation strategy under constrained generation systems [5]. Furthermore, the dynamic behavior on shipboard power systems has become more complicate due to increases in non-linear loads such as pulsed weapon systems [6]. This makes it difficult to secure the power quality.

To handle the above mentioned issues; limited system size, fuel efficient gen-set operation, improved power quality and so on, this paper proposes a novel IPS configuration and power control strategy for electric propulsion naval ships. The proposed IPS has Active Front End (AFE) converters directly connected battery Energy Storage Modules (ESMs). Like a conventional grid connected AFE converter, various advantages can be introduced to the electric power grid of naval ships. These include improved Total Harmonic Distortion (THD) in the current and voltage, reduced harmonic filters, no need for phase-shifting transformers, and a bidirectional power flow at the PCC (Point of Common Coupling) [7]. Moreover, the ESMs which are connected to the AFE converters provide the capability to compensate the lack of energy in contingencies such as generator trips. ESMs enable SGO, which increases the load factor of the generators and improves the fuel efficiency.

Since the AC/DC converters for ESMs are eliminated in the proposed configuration, the AFE converters should control the DC link voltage and the power of the ESMs simultaneously. To achieve these two objectives, a novel control algorithm for AFE converters is proposed. A conventional AFE converter controls only the DC link voltage for supplying power to the propulsion drive system. However, the proposed algorithm focuses on both the DC link voltage and the control of the power of the ESMs. Then, the DC link voltage can be maintained in a narrow voltage range decided by an additional ESM State-Of-Charge control. As a result, the ESMs can be controlled instantaneously without a dedicated converter.

\section{PROPOSED SYSTEM DESCRIPTION \& MODELING}

\section{A. Single Line Diagram}

Fig. 2 shows a notional single line diagram of the proposed IPS where the major sub-systems are depicted as the power generation system, electric propulsion system, zonal distribution system, and electrical loads system. Based on the specification of the reference ship given in the appendix, two Large Diesel-engine Generators (LDG) of 3.125MVA and two Small Diesel-engine Generators (SDG) of 1.25MVA are connected to the ahead or astern switchboard (SWBD) with its 


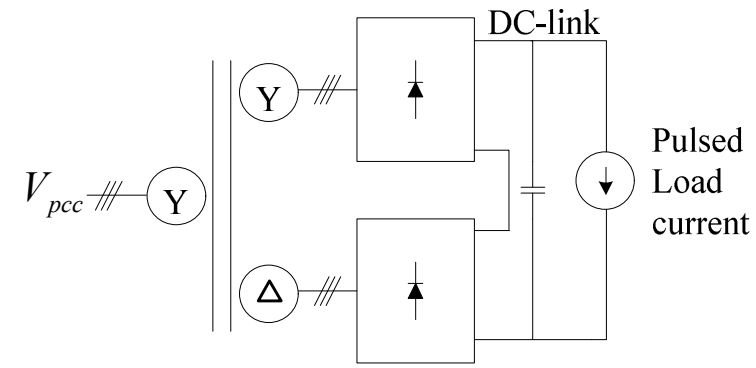

Fig. 3. Proposed propulsion system with AFE converter.

own circuit breaker. Each generator is a wound rotor synchronous generator and has an Automatic Voltage Regulator (AVR) and a Governor (GVR) as the voltage and frequency regulator. The total installed capacity of the generator sets on the ship should be enough to provide the maximum power demands at loading factor of less than $90 \%$ [8]. The system voltage on the main bus is determined by the short-circuit level and circuit breaker capability. In this IPS, it is set as a $690 \mathrm{Vrms}$ line-to-line. The zonal distribution system has 450 Vrms through step-down ship service transformers. In the electrical zone, the vital loads take dual power sources through the bus transfer devices.

In the proposed system, the future high power pulsed load is supposed to facilitate advanced weapon systems such as rail guns, high power lasers, pulsed sonar, etc. [9]. In the case of a high power laser, the required energy is known as several $\mathrm{MJ} / \mathrm{shot}$ and it is operated in continuous salvo mode. Therefore, future pulsed loads work with dedicated ESMs to reduce the peak power of the existing generation system. Most of studies for pulsed load systems are mainly focused on flywheel ESMs and on the mitigation of disturbances to the AC grid [10], [11]. In this paper, a notional pulsed load is modeled by a DC current source through a12-pulse diode rectifier, which has two secondaries in the $\mathrm{Y}$ and $\Delta$ transformers as shown in Fig. 3. The peak power demand and the duration of a pulse are assumed to be $5 \mathrm{MW}$ and $300 \mathrm{~ms}$ with $250 \mathrm{MW} / \mathrm{s}$ of pulse rising slew rate. In the proposed IPS, this intermittent pulsed power can be compensated with the proposed ESMs and the on-line generator set's total inertia without additional dedicated EMSs for pulsed load system itself. Therefore, the ESMs are installed for the pulsed power load and for improving the power quality and fuel efficiency.

\section{B. Propulsion Drive System}

To interface the propulsion motor drive system, which is the largest load to the generation system, to the AC grid of a ship, a Diode Front End (DFE) or AFE converter can be used. The DFE structure has been mostly adopted for high power full-IPSs. The DFE system has a simpler structure but suffers from a large THD of the input AC grid currents. Although a phase shifting transformer can be added to cope with this problem, it still needs a bulky harmonic filter to meet military

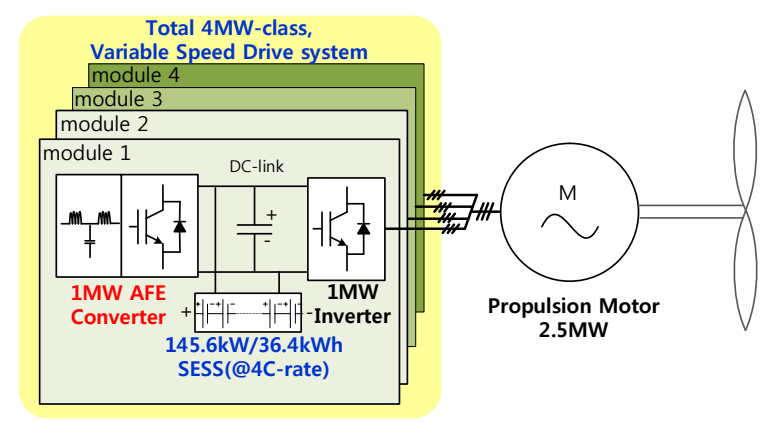

Fig. 4. Proposed propulsion system with AFE converter.

TABLE I

Li-ION Module SpecificAtions [15]

\begin{tabular}{|l|l|}
\hline C rate energy & $1.3 \mathrm{kWh}$ \\
Capacity at C rate & $31.25 \mathrm{Ah}$ \\
Nominal voltage & $41.27 \mathrm{~V}$ \\
Voltage limit $(20 \sim 100 \%)$ & $38 \sim 46 \mathrm{~V}$ \\
Max. discharging current & $4 \mathrm{C}$ \\
Cont. charging current & $0.5 \mathrm{C}$ \\
Weight & $16 \mathrm{~kg}$ \\
Volume $(\mathrm{L} \times \mathrm{W} \times \mathrm{H})$ & $0.371 \times 0.112 \times 0.211 \mathrm{~m}$ \\
Internal impedance & $10 \mathrm{~m} \Omega$ \\
\hline
\end{tabular}

harmonic standards [12]. With the transformer and filter, the structure becomes complex. As a result, both the size and the cost increase.

Recently, an AFE converter was applied to comparatively smaller power systems such as a hybrid-IPS [13]. A propulsion drive system with an AFE converter can enhance the power quality with reduced harmonic filters and there is no need for a phase shifting transformer. In addition, the system's weight and acoustic noise can be reduced. Furthermore, when ship maneuvering requires regenerative braking of the propulsion unit, the AFE converter gives an advantage to meet the stopping requirements with fewer dynamic braking resistors. The configuration of the AFE converter is usually a two-level or three-level structure. These structures have been successfully commercialized in industrial variable speed drives such as wind power generation and steel mill drive systems. With the development of high power semiconductor technologies, AFE converters are becoming more widely selected as the front end of high power propulsion drives. In this paper the bidirectional power flow capability of AFE converters is further exploited to interface battery-powered ESMs.

Fig. 4 shows the proposed AFE converter with an ESM. The battery-powered ESM is directly connected to the DC link of the propulsion drive system. Therefore, the power from the ESM can be transferred directly to the propulsion drive and to the AC grid without an additional power converter for the ESM. In general, large capacity shipboard ESMs are required to achieve the following purposes:

1) Uninterruptible power supply for vital-loads due to abnormal power quality variations such as voltage-sags 
or short circuit line faults.

2) Backup power supply for when the generator trips under single generator operation (SGO) or any generator fails at a high loading factor.

3) Emergency power supply for engine starting under the dead-ship condition.

4) Intermittent power source for high power pulsed loads.

The shipboard ESM is an essential component as a backup power source in contingency operations such as sudden failures of the operating generator or any fault in the IPS. In order to sustain the power continuity until the standby generator is synchronized in $45 \mathrm{~s}$ for hot-standby starting or $2 \mathrm{~min}$ for cold-standby starting, the power and energy rating of the ESMs can be calculated according to the load power demand. Nowadays, high power lithium-ion battery modules are being introduced into surface ship areas [14].

\section{Capacity of Proposed ESMS}

Based on the specifications of a high power lithium-ion module, as shown in Table I, the structure for the required capacity of the battery pack is presumed. In the proposed AFE configuration, the capacity of the ESM should be designed under the following three considerations: the DC voltage range, the power capacity, and the energy capacity. Since the battery voltage of the ESM is directly used as the DC link voltage, the battery voltage should be designed in the proper range of the Modulation Index (MI) of the AFE converter. Considering a $80 \sim 95 \%$ range of the MI, the voltage of the DC link should be ensured from $1027 \mathrm{~V}$ to $1220 \mathrm{~V}$. In addition, the operation range of the ESM's State of Charge (SOC) should be considered to be $30 \sim 80 \%$. Under this condition, the DC link voltage can be covered by a 28 -series connection of the modules in Table I.

Next, the power capacity should be considered. By considering the conventional generator-dispatch method in a ship, the practical power capacity of the ESMs for the required backup power of a single failure is around $700 \mathrm{~kW}$ in total. The maximum continuous discharging current of the battery module is supposed to be 4C. In the proposed IPS, shown in Fig. 2, there are two propulsion motor sets and each set consists of four converter modules. Therefore, four ESMs of $36.4 \mathrm{kWh}$ should be installed at each DC-link of a power conversion module as shown in Fig. 4.

Lastly, the energy capacity for back-up should be investigated. If a single failure of a generator-trip lasts for 3 minutes in the worst case, the required energy capacity is $35 \mathrm{kWh}$. The allowable SOC of the battery is from $30 \%$ to $80 \%$. Therefore, $50 \%$ of the total energy capacity of all of the modules should be larger than $35 \mathrm{kWh}$. Since one battery module has $1.3 \mathrm{kWh}, 54$ battery modules should be equipped in the power system. However, the power capacity and voltage capacity already require 224 battery modules, which have about $291 \mathrm{kWh}$. This energy capacity can easily provide back-up power for 3 minutes in the event of a worst case power failure, and the SOC of the ESMs drop only by around $15 \%$ even under the consideration of a higher rate of discharge.

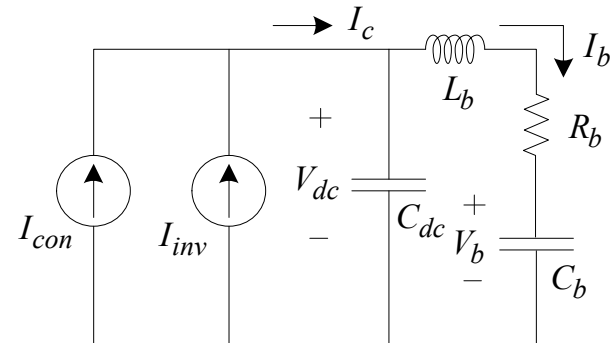

Fig. 5. Back-EMF estimator using disturbance observer.

According to Table I, the expected weight of the ESM package would be a total of about 8tons considering an additive weight factor of 2 to include the weight of the package of modules for military purposes. It should be emphasized that there is no additional DC/AC converter for the ESM itself and that the system's weight would be reduced over separated ESMs with dedicated converters.

\section{PROPOSED AFE CONVERTER CONTROL}

\section{A. Equivalent Model for the Proposed AFE Converter}

For the modeling of power flow at the DC link, the equivalent circuit is modeled as shown in Fig. 5. Two current sources are connected to the DC link, representing the current from the AC grid through the AFE converter and the current to the propulsion motor through the inverter, respectively. In addition, the battery ESM is modeled as a huge capacitor, $C_{b}$, charged with the open-circuit voltage of the battery, a constant internal series resistance, $R_{b}$, and a small interface inductance, $L_{b}$. The equivalent capacitance for the internal ESM voltage is calculated as (1).

$$
E_{b} \cdot \Delta \operatorname{SOC}(\%)=\frac{1}{2} C_{b}\left(V_{b \max }^{2}-V_{b \min }^{2}\right)
$$

where, $E_{b}$ stands for the stored energy in the ESMs, $\triangle S O C(\%)$ for the difference in state of charge of the ESMs in a percentage between the maximum SOC and the minimum SOC.

When the direction of the current flow is appointed, as shown in Fig. 5, the system equations can be derived as (2)-(4). The transfer function of the DC link regulation loop includes both a DC link capacitor and an equivalent battery capacitor.

$$
\begin{gathered}
V_{d c}=L_{b} \frac{d I_{b}}{d t}+R_{b} I_{b}+V_{b} \\
I_{c}=I_{c o n}+I_{i n v} \\
\frac{V_{d c}}{I_{c}}=\frac{s^{2} L_{b} C_{b}+s R_{b} C_{b}+1}{s^{3} L_{b} C_{b} C_{d c}+s^{2} R_{b} C_{b} C_{d c}+s\left(C_{b}+C_{d c}\right)}
\end{gathered}
$$

\section{B. Current Command of the ESM for Active Power Support}

The power command of the proposed ESM is activated by a frequency drop of the grid voltage at the PCC, i.e., SWBD. In the steady state, the frequency of the ship grid is regulated by 


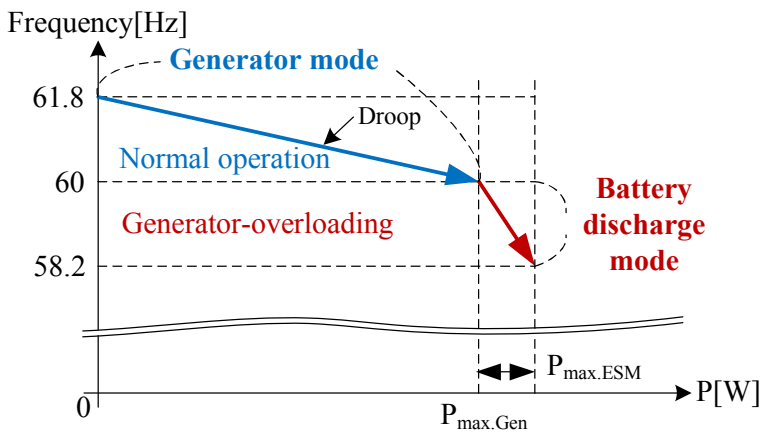

Fig. 6. Frequency tolerance and ESM support strategy.

the generator's governor within $3 \%$ tolerance. That is, the frequency under the no-load condition is $61.8 \mathrm{~Hz}$ and the frequency under the full load condition is $60 \mathrm{~Hz}$ as shown in Fig. 6.

In contingencies such as a one generator trip and/or a sudden pulse load employment, a further decrease of the frequency is allowable down to $58.2 \mathrm{~Hz}$, which is the lower bound in the steady-state. The conventional IPS configuration can provide additional power capability to the loads through the energy stored in the inertia of the generators including the prime mover at the cost of instability of the AC grid. However, this additional capability is very limited and there is always a risk of tripping the generator due to an under frequency fault if the situation of the contingency continues.

On the other hand, the proposed ESMs provide active power to the ship grid whenever the frequency of the PCC drops down from $60 \mathrm{~Hz}$. At $58.2 \mathrm{~Hz}$, the available maximum power of the ESM should be supplied to keep the frequency of the PCC from decreasing further. Fig. 7 shows a block diagram of the proposed ESM current command for supporting the overload condition at the PCC.

The current command for the ESM is proportional to the deviation of the PCC frequency, as seen from (5), when it is out of the specified dead-band. In this system, to provide the maximum ESM power, $P_{b \max }$, at the minimum allowable grid frequency, $58.2 \mathrm{~Hz}$, the gain for the current command of the ESM, $K_{f}$, is set as (6). The operation mode of the ESM according to the PCC conditions is depicted in Fig.8.

$$
\begin{gathered}
I_{b}^{*}=K_{f} \cdot \Delta f_{\text {mod }}=\frac{P_{b}^{*}}{V_{d c}} \\
K_{f}=\frac{P_{b \max }}{1.8 V_{d c}}
\end{gathered}
$$

\section{Control Scheme for the Proposed System}

By assuming that the sampling frequency is sufficiently high and that the back-EMF is constant during a sampling period, the dynamic equations of a PMSM based on the extended EMF model are given as follows. The proposed AFE configuration has two roles: supplying active power to the

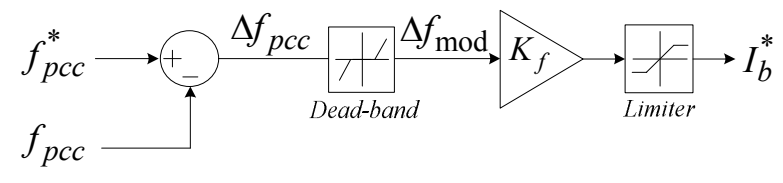

Fig. 7. ESM current command for active power support.

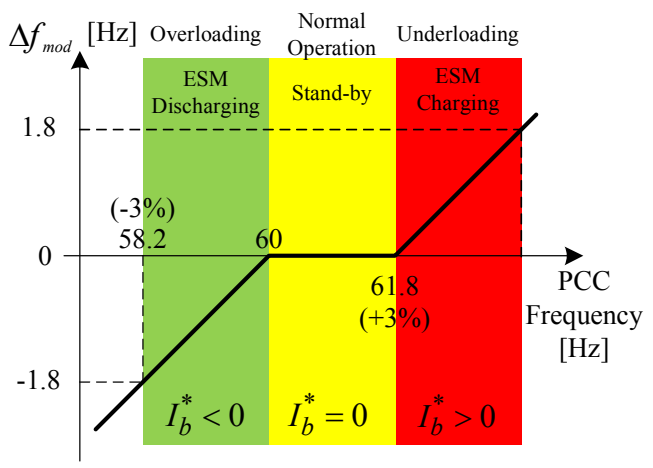

Fig. 8. ESM operation mode.

motor drive system under the normal condition, and providing active power into the grid under contingencies such as a generator trip or a sudden pulse load deployment. Under the normal condition, if the SOC of the battery ESMs is under $80 \%$, the additional active power to charge the ESMs in the $0.5 \mathrm{C}$ rate are provided from the ship grid. When the battery is fully charged, the battery current under the normal condition should be zero for the elimination of unnecessary losses in the ESMs. In the deceleration of a ship, the regenerated energy of the propulsion motor drive system is, at first, transferred to the ship grid through the AFE. If there are not enough loads in the grid, the frequency of the PCC will increase with the excess regenerated power. In addition, the current command for the ESM will be positive to absorb the excess regenerated power according to (5). With this control strategy, dynamic braking resistors are not needed in the proposed IPS. This simultaneously improves the power density of the IPS and enhances the fuel efficiency.

Fig. 9 shows the control scheme for the AFE with directly connected ESMs. Conventionally, the AFE converter has a DC link voltage controller as shown in Fig. 9(a). Based on this conventional DC link voltage control, the power control function of the ESMs can be added for contingencies and also for the charging of the ESMs. When the battery is fully charged under the normal condition, the voltage controller usually works to maintain the DC voltage. However, in this conventional scheme, the control mode needs to be changed seamlessly. Moreover, the battery current in the normal condition can vary according to the power disturbance between the converter and the inverter. This power mismatch causes frequent operation of the ESMs, which makes an additional loss and reduces the battery lifetime.

To improve the control performance by minimizing the battery current under the normal condition, a novel controller is 


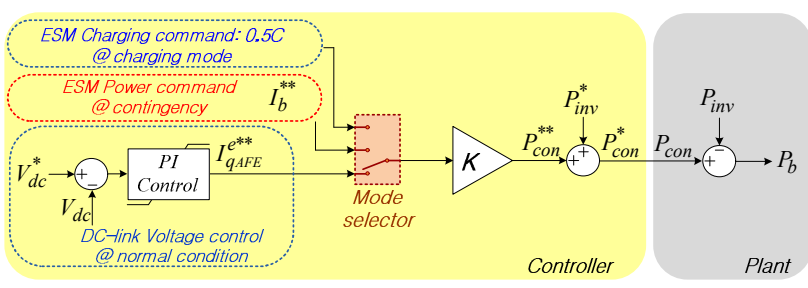

(a) Conventional control scheme based on the DC link voltage control.

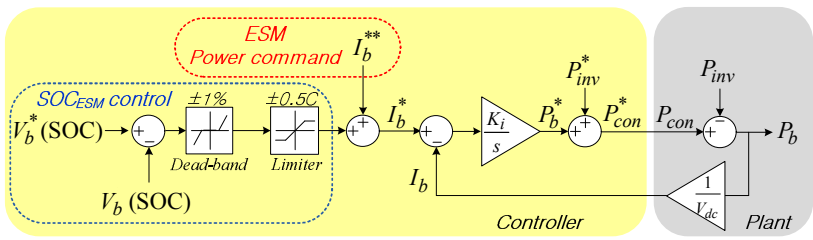

(b) Proposed control scheme based on battery current control.

Fig. 9. Control scheme for the AFE with ESM.

proposed as shown in Fig. 9(b). This controller primarily controls the battery current instead of the DC link voltage. The DC link voltage is adjunctively controlled by the battery SOC controller. The information on the battery SOC can be obtained from a general Battery Management System (BMS), which should be installed in the ESMs. When the SOC is out of the $2 \%$ bound under the normal condition, the battery is charged in the $0.5 \mathrm{C}$ rate. Under contingencies, the power reference from Fig. 7 is used as the battery current reference. To control the battery current, a simple integral controller can be adopted to derive the transfer function of the reference and real battery current as a low-pass-filter as seen from (7).

$$
\frac{I_{b}}{I_{b}^{*}}=\frac{K_{i}}{s+K_{i}}
$$

A power disturbance in the grid or the DC link can cause the battery current, the voltage controller and the current controller, in Fig. 9(a) and 9(b), try to and compensate the power disturbance. The controller's response to the power disturbance, $P_{d}$, can be described as (8) and (9), respectively.

$$
\begin{gathered}
\frac{P_{c o n}^{*}}{P_{d}}=-\frac{K_{p} s+K_{i}}{C_{b} s^{2}+K_{p} s+K_{i}} \\
\frac{P_{c o n}^{*}}{P_{d}}=-\frac{K_{i}}{s+K_{i}}
\end{gathered}
$$

In the conventional voltage control scheme, the PI gain in the controller is designed with the DC link capacitor. However, the plant has a huge equivalent capacitor of the battery. Even though the voltage controller is designed as a $5 \mathrm{~Hz}$ bandwidth with consideration of the DC link capacitor, because of the huge capacitance of the battery, the response of power controller, $P_{c o n}^{*}$, according to the power disturbance is extremely sluggish. On the other hand, the proposed battery current controller generates the power reference of the AFE converter directly from the error of the battery current, and the control

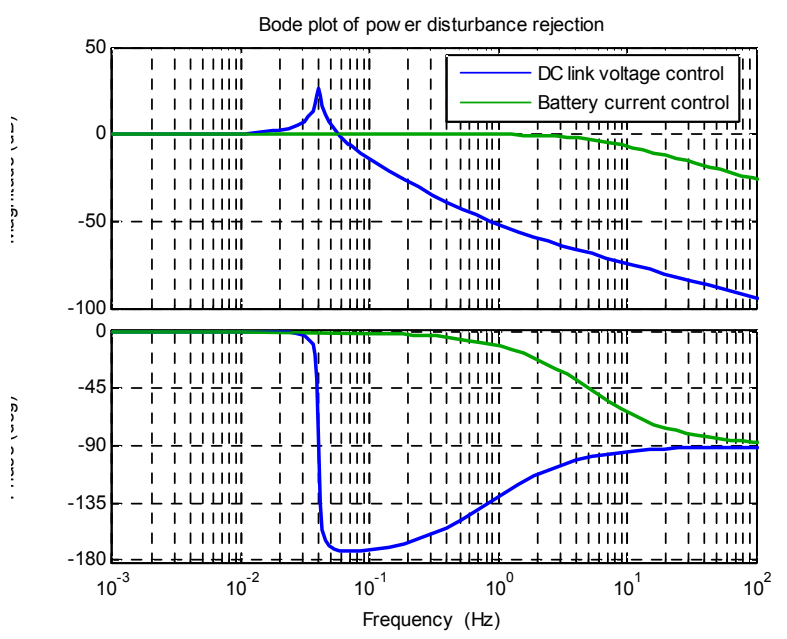

Fig. 10. Bode plot of power disturbance rejection.

bandwidth can be increased up to several Hz. Fig. 10 shows bode-plots of the power disturbance rejection of both control algorithms.

\section{SYSTEM MODELING AND PHILS}

This paper utilizes two simulation tools: the MATLAB/Simulink for mathematical models with controllers, and the PLECS circuit to compose the electric power network as shown in Fig. 11. Each generator set is implemented as a well-known $5^{\text {th }}$ order dynamic model and each controller such as the GVR and AVR are modeled based on a standard PID controller and an IEEE Type-I excitation system [16], [17]. Block diagrams of controller and the specific parameters are given in the appendix.

To verify the proposed control scheme for the AFE converter, a simple condition is considered: a generator and an AFE converter with a $2 \mathrm{MW}$ propulsion load. Therefore, the AFE converter works under the normal mode without any discharging of the ESM. To minimize the loss in the ESMs, the current through the ESMs should be minimized. In Fig. 12, the AFE power, the battery current, and the losses caused by the battery resistance are shown according to the control algorithm. Even through the conventional voltage control scheme makes over $1.2 \mathrm{~kJ}$ in loss for a given AFE power flow, the proposed current control scheme has less than 100J of loss under the same power flow of the AFE.

The real time Power Hardware-In-the-Loop (PHIL) experiment proceeds based on this shipboard power system modeling. Systematic testing of the shipboard IPS is increasingly important as the complexity of the system has greatly increased. The PHIL consists of a Hardware-In-the-Loop Simulation (HILS) part and a hardware part. The devices which cannot be implemented in hardware 


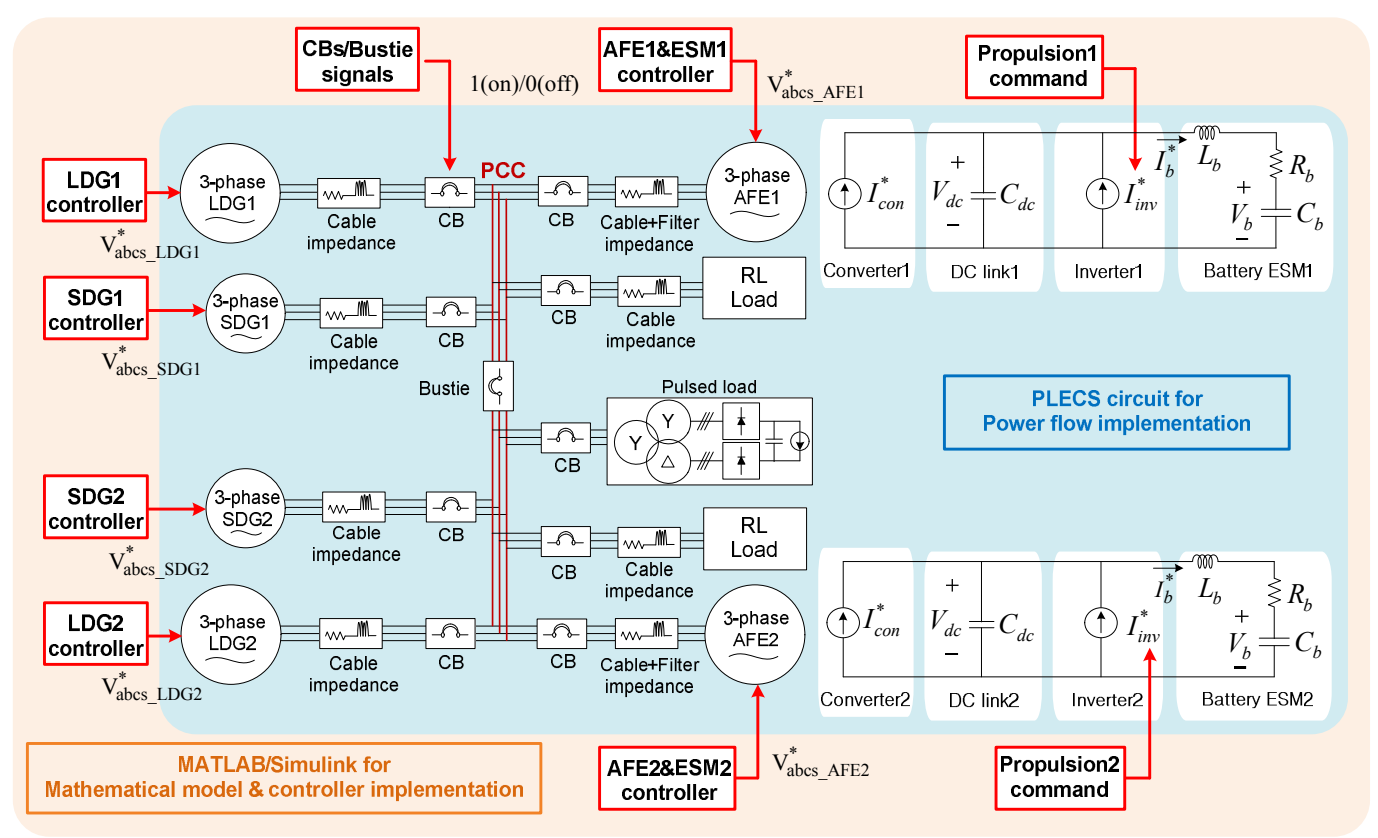

Fig. 11. System modeling by MATLAB/Simulink and PLECS.
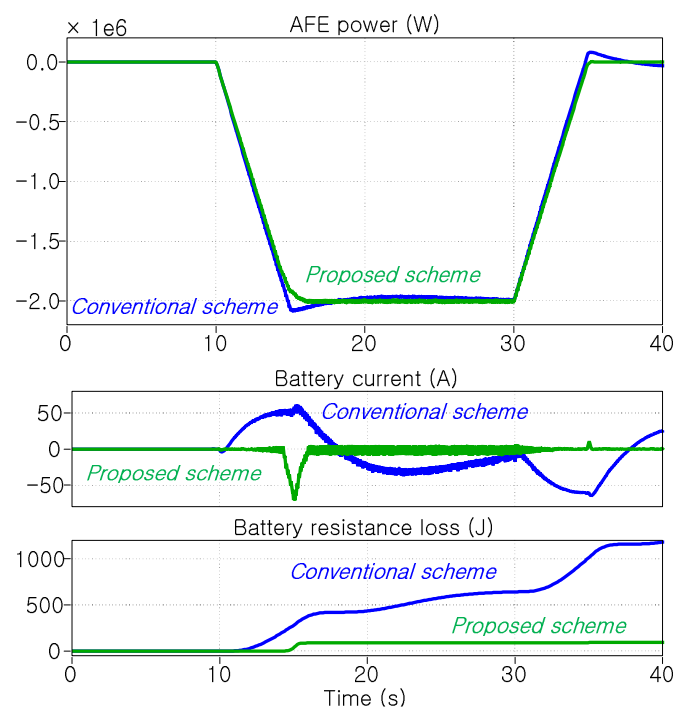

Fig. 12. Normal operation of AFE converter.

due to time, cost and safety issue are modeled in the HILS. PHILS testing is widely used in order to verify the functionality of the designed IPS [18], [19]. The entire HILS set-up to verify the proposed system performance and failure handling is described in Fig. 13. The ship's electrical power system, as shown in Fig. 2, is emulated in the real time HILS using a TMS320C6678, TI multicore DSP. The IPS circuit is coded in $\mathrm{C}$ language after being modeled in differential equations or circuits. The IPS circuits are partitioned into 4 generators including the GVR, AVR, RL load, and pulse load, and the partitioned circuits are simulated in each core. The circuit partition is based on the Ideal Transformer Model (ITM).
One of the partitioned generator circuits is assigned as a swing bus which calculates the PCC voltage. This PCC voltage is used to calculate the currents in other the partitioned circuits; namely, the other three generator circuits, the RL load circuit, and the pulse load circuit. These loads currents are returned to the swing bus circuit as feedback in the current source form and the swing bus circuit calculates the PCC voltage using the feedback currents. The time delay in this feedback loop effects the stability of the HILS. The minimum time delay is one sampling time which is set as $25 \mu \mathrm{s}$ in this paper.

The AFE converter (INV2), BESS, and the propulsion motor and its inverter (INV3) are implemented in small scaled hardware. The INV2 performs the SOC control and power compensation according to the proposed control methods. The INV3 performs the speed control of the propulsion motor according to the ship speed reference. The PCC voltage is down scaled from $690 \mathrm{~V}_{\mathrm{LL}, \mathrm{rms}}$ to $200 \mathrm{~V}_{\mathrm{LL}, \mathrm{rms}}$, which is $3.45: 1$. The power is down scaled by a 1000:1 ratio, from a $5 \mathrm{MW}$ propulsion load to a $5 \mathrm{~kW}$ load. Therefore, the current is down scaled by $290: 1$. The propulsion motor plant is implemented as the Motor-Generator set with an inverter (INV4). The ship hydrodynamic model is implemented as software in DSP board3 and the ship speed is communicated to DSP board2 through Digital to Analog (DA) and Analog to Digital (AD) communication. The mechanical dynamics of the propulsion motor including its inertia are preserved after the scaling, by scaling the speed of the propulsion motor to 1:6.67.

The connection between the PCC in the HILS and the AFE converter in hardware was achieved by the PCC voltage amplifier (INV1). The PCC voltage amplifier consists of a 3 level T-type inverter with a switching frequency of $20 \mathrm{kHz}$ and 

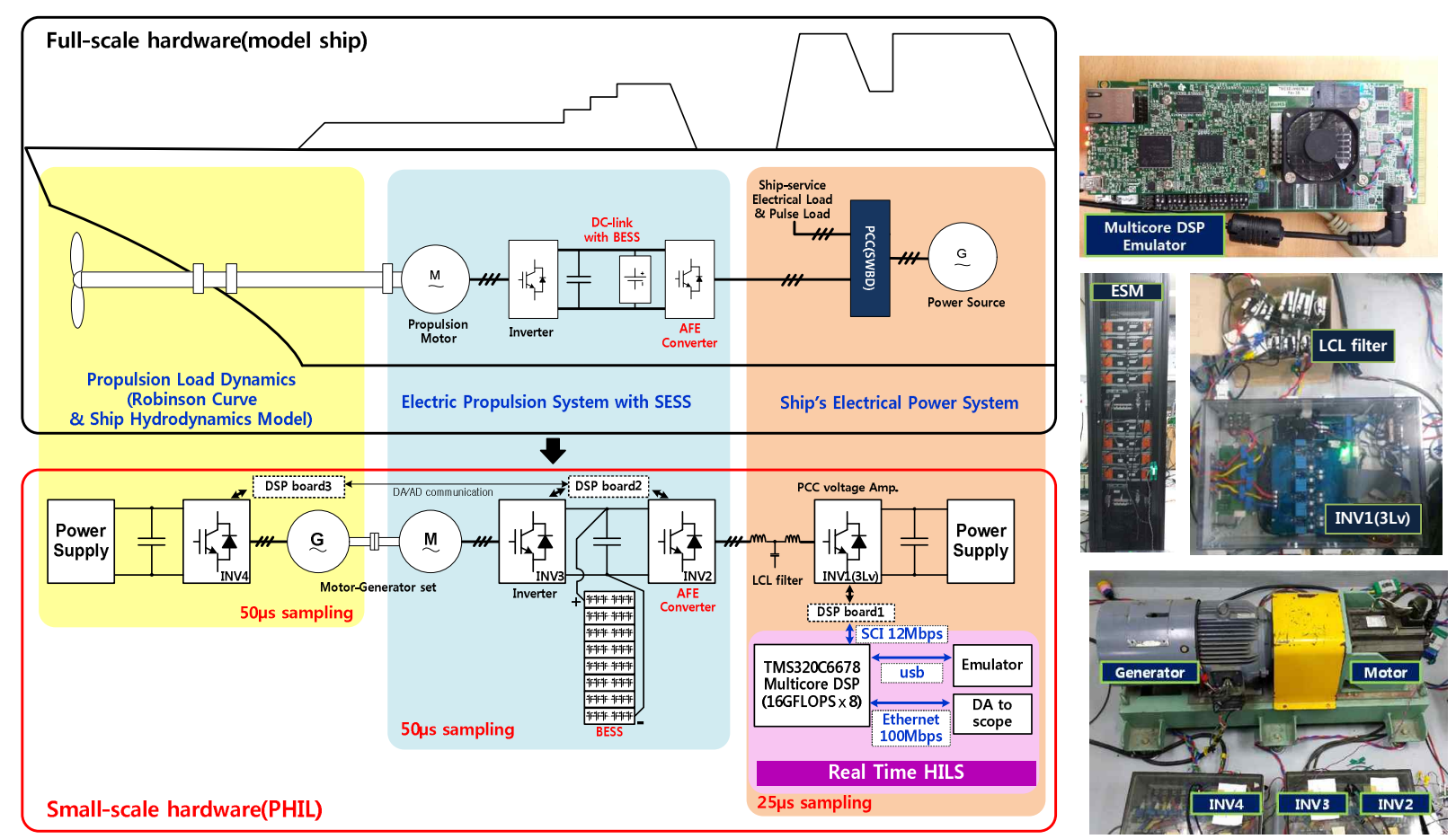

Fig. 13. PHIL experimental setup of shipboard power system.

a sampling frequency of $40 \mathrm{kHz}$ to make the sampling time $25 \mu$ s equal to the sampling time of the HILS, and an LCL filter to reduce the grid voltage harmonics. The PCC voltage amplifier synthesizes the PCC voltage in a power level whose reference is calculated in the swing bus circuit in the HILS and returns back the sensed AFE current to the swing bus circuit. Both the communications and the HILS calculation should finish in less than the sampling time, $25 \mu \mathrm{s}$. The $12 \mathrm{Mbps}$ SCI communication was utilized for this purpose. The 100Mbps Ethernet and DA were also utilized to send the data of the HILS to an oscilloscope through the PC to display the data in real time.

In this paper, a lithium-ion battery pack of $25.6 \mathrm{kWh}$ was applied to the small scaled hardware, instead of the proposed capacity of the ESM, due to the limitations of the available battery pack. The battery pack consists of 8-series module $(3.2 \mathrm{kWh} /$ module) in the rack. Therefore, the capacity of the EMSs for the small-scaled experiment is relatively too large when compared to the proposed capacity of the ESM. As a result, it is hard to observe the SOC variation. Therefore, in this paper, the performance of the proposed system is not verified through the SOC but though the battery output current.

\section{EXPERIMENTAL RESULTS}

As a scenario of the N-1 contingency mode, SDG1 is tripped during the efficient cruising mode when LDG1, SDG1 and 2 are on line with almost a $90 \%$ loading factor. The rated capacity of all of the on-line generators is $4.5 \mathrm{MW}$ and SDG demanded load power is $4 \mathrm{MW}$. Therefore, the trip of SDG1 makes the system over load. Despite the fact that the generator's governor (GVR) reaches its maximum output, the frequency drastically drops out within a few seconds and the system is eventually blacked out as shown in Fig. 14. From the top, the total generation power, the governor output of LDG1, the PCC phase voltage, the PCC phase current, the PCC line to line voltage magnitude, the PCC frequency, the AFE q-axis current, and the battery current are shown. Figure 15 shows the experimental result of the ESMs power compensation for the generator trip mode. When SDG1 is tripped in the same operating condition, the current of the battery ESMs increases and the PCC frequency is maintained within the normal deviation region of $+/-3 \%$. The q-axis current of the AFE decreases during the generator trip mode due to the power support from the ESM. A stand-by generator, LDG2, is brought onto the PCC network after 120s, which is a typical synchronizing time of a cold stand-by generator. After end of the discharging mode, the ESMs is charged with a constant charging current by the diesel-engine generators and the DC-link voltage is restored to the nominal voltage as designed. As mentioned before, the SOC is nearly constant in this experimental condition, and the charging mode of the ESMs is hard to observe.

\section{CONCLUSIONS}

This paper proposes a novel configuration of an integrated power system for advanced electric propulsion naval ships. The proposed propulsion drive unit consists of an AFE converter 


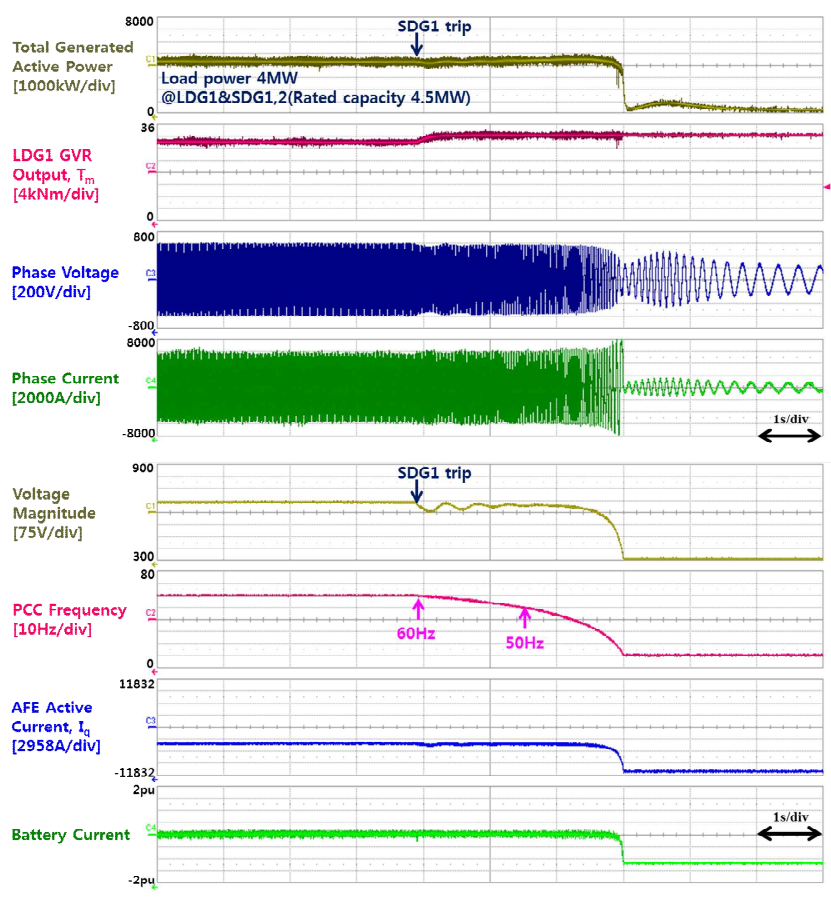

Fig. 14. Generator trip mode (before ESMs compensation).

with a directly connected battery ESM. Therefore, there is no dedicated DC/DC or DC/AC converters for the ESM. Instead the existing AFE converter of the electric propulsion system and its controller perform charging and discharging current control of the ESM simultaneously with DC-link voltage control. To do this, a voltage DC link power controller has been devised with a battery current regulation loop. The performance of the proposed controller has been compared with that of a conventional voltage controller, and it has been revealed that the proposed controller has better control performance against power disturbances and higher operating efficiency in terms of the internal losses of ESMs. Then, the system-level performance of the proposed IPS is verified by a small scaled experiment using PHIL. The generator sets, the ship-service load, and the pulse load were modeled and implemented as partitioned circuits in the low cost multicore HILS. The AFE converter, the ESMs, and the propulsion motor were implemented as hardware. From the PHIL experiment, the control algorithm of the AFE to compensate the PCC frequency has been verified under the condition of the generator trip mode.

The proposed ESMs improve the fuel efficiency of the generators due to an increased steady-state loading factor. Moreover, contingency operations such as generator trips and pulse load employment can be achieved without additional generators or load shedding. The proposed IPS and its associated control scheme enhance the reliability and availability of ship power and, simultaneously, fuel efficiency under both normal and contingency operating modes. In conclusion, the proposed system can be considered as a practical candidate for an IPS in next generation electric

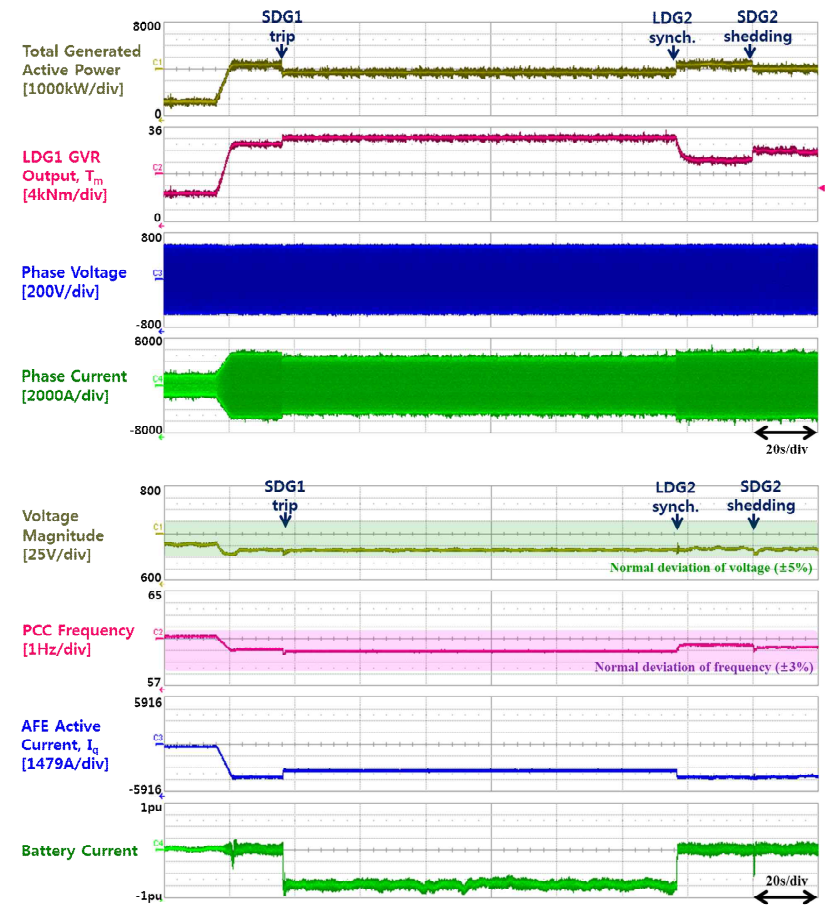

Fig. 15. Generator trip mode (after ESMs compensation).

propulsion naval ships.

\section{APPENDIX}

Reference ship's specifications:

Tonnage: 4000 ton class

Max. Ship speed: $18 \mathrm{kts}$

LDG data:

$\mathrm{S}_{\text {rated }}=3.125[\mathrm{MVA}], \mathrm{R}_{s}=0.00128[\Omega], \mathrm{L}_{l s}=53[\mu \mathrm{H}]$,

$\mathrm{L}_{m d}=\mathrm{L}_{m q}=800[\mu \mathrm{H}], \mathrm{R}_{f k}^{\prime}=0.003[\Omega], \mathrm{L}_{l f k}^{\prime}=57[\mu \mathrm{H}]$,

$\mathrm{R}_{d k}^{\prime}=\mathrm{R}_{q k}^{\prime}=0.0108[\Omega], \quad \mathrm{L}_{l d k}^{\prime}=\mathrm{L}_{l q k}^{\prime}=15[\mu \mathrm{H}]$,

$J_{L D G}=656\left[\mathrm{~kg} \cdot \mathrm{m}^{2}\right]$, Number of poles $=8$

SDG data:

$\mathrm{S}_{\text {rated }}=1.25[\mathrm{MVA}], \mathrm{R}_{s}=0.0034[\Omega], \mathrm{L}_{l s}=105[\mu \mathrm{H}]$,

$\mathrm{L}_{m d}=\mathrm{L}_{m q}=2900[\mu \mathrm{H}], \mathrm{R}_{f k}^{\prime}=0.003[\Omega], \mathrm{L}_{l f k}^{\prime}=145[\mu \mathrm{H}]$,

$\mathrm{R}_{d k}^{\prime}=\mathrm{R}_{q k}^{\prime}=0.024[\Omega], \quad \mathrm{L}_{l d k}^{\prime}=\mathrm{L}_{l q k}^{\prime}=60[\mu \mathrm{H}]$,

$J_{S D G}=100\left[\mathrm{~kg} \cdot \mathrm{m}^{2}\right]$, Number of poles $=4$

AFE converter:

$\mathrm{R}_{i}=0.0019[\Omega], \mathrm{L}_{i}=200[\mu \mathrm{H}], \mathrm{C}_{d c}=0.01[\mathrm{~F}]$,

Bandwidth of current controller: $200 \mathrm{~Hz}$

Bandwidth of voltage controller: $5 \mathrm{~Hz}$

Battery ESM (per module):

$\mathrm{C}_{b}=805.5[\mathrm{~F}], \quad \mathrm{R}_{b}=0.14[\Omega], \mathrm{L}_{b}=10[\mu \mathrm{H}], \quad K_{f}=569.2$ 


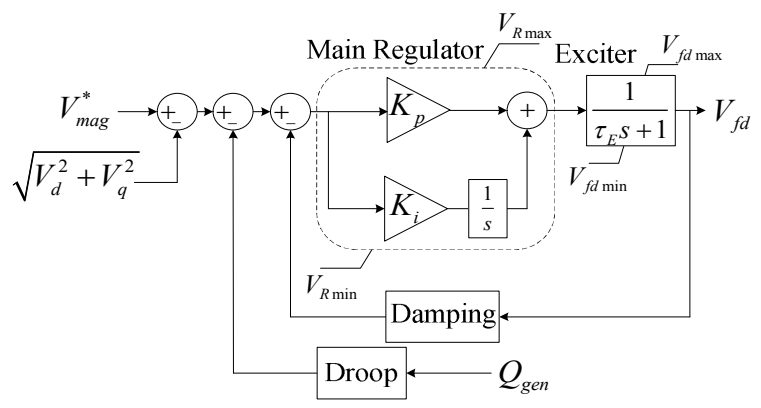

(a) Block diagram of the Automatic Voltage Regulator.

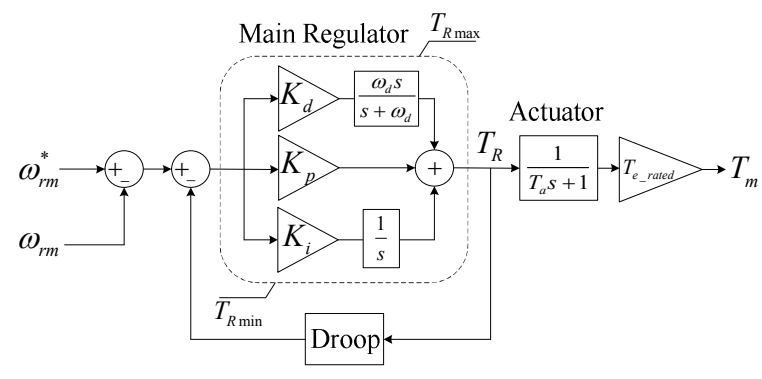

(b) Block diagram of the Governor.

Fig. 16. Block diagram of the generator's controller.

Automatic Voltage Regulator (Fig. 16(a)):

$$
\begin{aligned}
& K_{p \mathrm{LDG}}=0.1, K_{i \mathrm{LDG}}=0.1, \tau_{E \mathrm{LDG}}=0.002, \\
& K_{p \mathrm{SDG}}=0.2, K_{i \mathrm{SDG}}=0.2, \tau_{E \mathrm{SDG}}=0.001, \\
& V_{R \max }=E_{f d \max }=10, \text { damping }: \frac{0.001 s}{0.1 s+1}
\end{aligned}
$$

Governor(Fig. 16(b)):

$$
\begin{aligned}
& K_{p \mathrm{LDG}}=30, K_{i \mathrm{LDG}}=40, K_{d \mathrm{LDG}}=0.05, T_{a \mathrm{LDG}}=0.15 \text {, } \\
& K_{p \mathrm{SDG}}=60, K_{i \mathrm{SDG}}=40, K_{d \mathrm{SDG}}=0.05, T_{a \mathrm{SDG}}=0.15 \text {, } \\
& T_{R \max }=100, T_{R \min }=0, \omega_{d}=100
\end{aligned}
$$

\section{REFERENCES}

[1] T. Ericsen, N. Hingorani, and Y. Khersonsky, "Power electronics and future marine electrical systems," IEEE Trans. Ind. Appl., Vol. 42, No. 1, pp.155-163, Jan./Feb. 2006.

[2] S. D. Sudhoff, "Currents of Change," IEEE Power Energy, Vol. 9, No. 4, pp. 30-37, Jul./Aug. 2011.

[3] L. Qi, J. Pan, Z. Wang, J. Daniel, and O. Apeldoorn, "Integrated power system modeling and simulation," Electric Ship Technologies Symposium (ESTS), 2011 IEEE, pp. 90-95, 2011.

[4] B. Zahedi, and L. E. Norum, "Modeling and simulation of all-electric ships with low-voltage DC hybrid power systems," IEEE Trans. Power Electron., Vol. 28, No. 10, pp. 4525-4537, Oct. 2013.

[5] S. Y. Kim, B. G. Cho, and S. K. Sul, "Feasibility study of integrated power system with battery energy storage system for naval ships," Vehicle Power and Propulsion Conference (VPPC), 2012 IEEE, pp. 532-537, 2012.

[6] L. J. Petersen, D. J. Hoffman, J. P. Borraccini, and S. B. Swindler, "Next-generation power and energy: maybe not so next generation," Naval Engineers Journal, Vol. 122, No. 4, pp. 59-74, Dec. 2010.

[7] G. Sulligoi, S. Castellan, M. Aizza, D. Bosich, L. Piva, and G. Lipardi, "Active front-end for shaft power generation and voltage control in FREMM frigates integrated power system: Modeling and validation," Power Electronics, Electrical Drives, Automation and Motion (SPEEDAM), 2012 International Symposium on, pp.452-457, 2012.

[8] IEEE Recommended Practice for Electrical Installations on Shipboard, IEEE Std 45-2002 (Revision of IEEE Std 45-1998), pp. 0 1-258, 2002.

[9] J. J. A. Van der Burgt, P. van Gelder, and E. van Dijk, "Pulsed power requirements for future naval ships," Pulsed Power Conference, 1999. Digest of Technical Papers. 12th IEEE International, Vol. 2, pp. 1357-1360, 1999.

[10] R. E. Hebner, J. D. Herbst, and A. L. Gattozzi, "Pulsed power loads support and efficiency improvement on navy ships," Naval Engineers Journal, Vol. 122, No. 4, pp. 23-32 Dec. 2010.

[11] F. Scuiller, "Simulation of an energy storage system to compensate pulsed loads on shipboard electric power system," Electric Ship Technologies Symposium (ESTS), 2011 IEEE, pp.396-401, 2011.

[12] MIL-STD-1399(NAVY) Interface Standard Sec.300B, Electric power, alternating current, 2008

[13] G. Sulligoi, D. Bosich, T. Mazzuca, and L. Piva, "The FREMM simulator: A new software tool to study electro-mechanic dynamics of the shipboard integrated power system," Electrical Systems for Aircraft, Railway and Ship Propulsion (ESARS), pp. 1-6, 2012.

[14] M. Dennis, L. Don, H. John, and M. Jeff, "Advanced shipboard energy storage system," ASNE EMTS Symposium on, 2012.

[15] Data sheet of Saft VL34P - high power cell, Saft America, Inc., http://www.saftbatteries.com/market-solutions/marine, Dec 18th 2013.

[16] IEEE Recommended Practice for Excitation System Models for Power System Stability Studies, IEEE Std 421.5-2005 (Revision of IEEE Std 421.5-1992), pp.0_1-85, 2006.

[17] S. K. Sul, Control of Electric Machine Drive Systems, 1st Ed., Ch. 3, Wiley-IEEE Press, 2011,

[18] Y. Liu, M. Steurer, and P. Ribeiro, "A novel approach to power quality assessment: real time hardware-in-the-Loop test bed," IEEE Trans. Power Del., Vol. 20, No. 2, pp. 1200-1201, 2005.

[19] R. Ahmadi, H. Behjati, and M. Ferdowsi, "Dynamic modeling and stability analysis of an experimental test bench for electric-ship propulsion," Electric Ship Technologies Symposium (ESTS), IEEE, pp. 110-115, 2013.

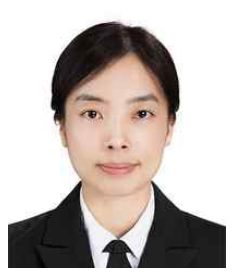

So-Yeon Kim was born in Gangneung, Korea, in 1980. She received her B.S. degree in Electrical Engineering from the Republic Of Korea Naval Academy, Changwon, Korea, in 2003, and her M.S. degree in Electrical Engineering from Seoul National University, Seoul, Korea, in 2007, where she is currently pursuing her Ph.D. degree. From 2003 to 2004, she was in the military service serving on a warship. From 2007 to 2009, she was a Lecturer with the Department of Electrical Engineering of the ROK Naval Academy. Her current research interests include electric/hybrid ship drives and shipboard energy storage systems. 


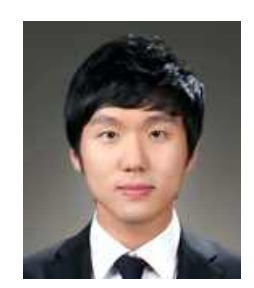

Sehwa Choe received his B.S. and M.S. degrees in Electrical Engineering and Computer Science from Seoul National University, Seoul, Korea, in 2011 and 2013, respectively, where he is currently pursuing his $\mathrm{Ph} . \mathrm{D}$. degree. His current research interests include the sensorless control of electrical machines and capacitor-less inverters.

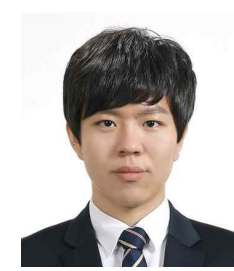

Sanggi Ko was born in Ulsan, Korea, in 1989. He received his B.S. degree in Electrical Engineering from Seoul National University, Seoul, Korea, in 2012, where he is currently pursuing his M.S. degree in Electrical and Computer Engineering. His current research interests include motor drives, power converters, electric vehicles and renewable energy.

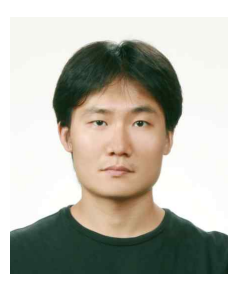

Sungmin Kim was born in Seoul, Korea, in 1980. He received his B.S. and M.S. degrees in Electrical Engineering from Seoul National University, Seoul, Korea, in 2002, 2008, respectively, where he is currently pursuing his Ph.D. degree. His current research interests include power electronic control of electric machines, sensorless drives, matrix converter drives, power conversion circuits, and HVDC power transmission systems.

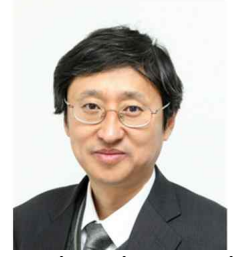

Seung-Ki Sul was born in Korea, in 1958. $\mathrm{He}$ received his B.S., M.S., and Ph.D. degrees in Electrical Engineering from Seoul National University, Seoul, Korea, in 1980, 1983, and 1986, respectively. From 1986 to 1988, he was an Associate Researcher in the Department of Electrical and Computer Engineering, University of Wisconsin, Madison, Wisconsin, USA. From 1988 to 1990, he was a Principal Research Engineer with Gold-Star Industrial Systems Co., Korea. Since 1991, he has been a member of the faculty in the School of Electrical Engineering, Seoul National University, where he is currently a Full Professor. Since 2000, he has been an IEEE Fellow. From 2003 to 2004, he was a Research Director and an Acting Consultant for Yaskawa Electric Co., Japan. From 2005 to 2007, he was the Vice Dean of the Engineering College of Seoul National University. In addition, from 2008 to 2011, he was the President of the Electrical Engineering Science Research Institute funded by the Korean Government. He has published over 120 reviewed journal papers, mainly IEEE transactions. He was Technical Chair of the IEEE PESC2006 conference and General Chair of the IEEE ECCE-Asia 2011. He is currently Editor-in-Chief of the Journal of Power Electronics, which is a SCIE registered journal, published by the Korean Power Electronics Institute, Seoul, Korea. His current research interests include power electronic control of electrical machines, electric/hybrid vehicles and ship drives, and power-converter circuits for renewal energy sources. 